\title{
Study of Utilization of Integrated Disease Surveillance and Response Data in Controlling Infectious Diseases among Public Health Facilities in Kiambu County, Kenya
}

\author{
Ferdinand Wabwile Milliano ${ }^{1}$, Prof. Ephantus Kabiru ${ }^{2}$, Dr. George O. Otieno ${ }^{3}$ \\ Research Scholar ${ }^{1}$, Professor $^{2}$, Doctor $^{3}$ \\ Department of Community Health and Epidemiology \\ School of Public Health and Applied Human Sciences \\ Kenyatta University \\ Nairobi, Kenya
}

\begin{abstract}
Integrated Disease Surveillance and Response entails data collection, analysis, interpretation, and feedback on communicable and non-communicable diseases. It enables health workers to detect and respond to these diseases. Poor utilization of disease surveillance and response data was identified as a core factor responsible for increasing mortality and morbidity due to infectious diseases in developing countries like Kenya. This study assessed utilization of Integrated Disease Surveillance and Response data in control of infectious diseases among Public health facilities in Kiambu County, Kenya. It specifically investigated the proportion of Health workers trained on IDSR, level of knowledge regarding IDSR and Health system factors influencing IDSR utilization. This was a descriptive cross-sectional survey. It involved public health facilities with key respondents being the health care workers providing curative and preventive health services within the selected health facilities. Stratified sampling technique was used to stratify the 108 health facilities into levels of health care while proportionate sampling was used to select 143 participants in the respective level of care. An interviewer-administered questionnaire was used to collect data which was entered and analysed using the Statistical Package for Social Sciences (SPSS) software version 20. Chi-square test of independence was used to assess the associations between utilization of IDSR data, training, level of knowledge and health system factors while Regression analysis was used to establish the predictors of utilization of IDSR data. Utilization of IDSR index score shows 64.9\% inadequate utilization of IDSR data. The available data has not been adequately utilized to inform action plans, public education, and resource mobilization. The study shows that $13.7 \%$ of health care workers had been adequately trained on IDSR while 75\% had moderate knowledge of IDSR function. Accordingly, 54.6\% of respondents had the opinion that there were inadequate essential supplies for IDSR. Chi-square analysis shows that the respondent's duration of practice $\chi 2(2.437, d f=3, p=0.045)$ and level of knowledge on IDSR were associated with utilization of IDSR data $\chi^{2}(0.227 \mathrm{df}=2, p=0.048)$. Logistic regression analysis illustrates that the level of knowledge (A.O. $R=1.55, p=0.041$ ) and Cadre of respondents (A.O. $R=0.827, p=0.023$ ) were predictors of utilization of IDSR data.
\end{abstract}

Key Words: Integrated Disease Surveillance and Response, Utilization, Infectious diseases, Control.

\section{INTRODUCTION}

In Africa, infectious diseases are still the most common causes of morbidity and mortality. To effectively control these diseases, health systems need access to complete, accurate and timely Information for effective planning [1]. The Integrated Disease Surveillance and Response (IDSR) strategy was instituted by World Health Organization Africa Regional Office in 1998 with an objective to strengthen the availability and use of surveillance data for detecting, reporting, investigating, confirming, and responding to preventable priority diseases as well as other Public health events [2]. Kenya adopted the IDSR strategy in 1998 following the World Health Organization Resolution in Harare 
and started implementation in 2002 . The country selected a total of 35 priority diseases for reporting that are epidemic prone, targeted for elimination or eradication, or are of public health importance [3].

Communicable diseases remain the leading cause of morbidity and mortality in Kiambu County. According to County records, incidences of infectious diseases such as Diarrhoea, Cholera, Typhoid, Dysentery, Rabies, Anthrax, Measles, Meningococcal meningitis, and malaria have been on the increase since 2015 . The county reported 136 cases of cholera with 7 deaths (CFR 5.1\%) in 2015 alone. Conditions such as maternal deaths and non-communicable diseases such as hypertension and diabetes have also been on increase. This is despite all Public health facilities adopting IDSR strategy which is expected to strengthen the availability and use of surveillance data for detecting, reporting, investigating, confirming, and responding to preventable priority diseases as well as other public health events. Poor utilization of Integrated Disease Surveillance and Response data was identified as one of the major factors responsible for increasing mortality and morbidity due to infectious diseases in developing countries like Kenya [4]. There is no available information on utilization of disease surveillance data in Kiambu County. This therefore creates need to assess the utilization of IDSR Data among health workers in Public Health facilities

The study aimed at assessing utilization of Integrated Disease Surveillance and Response data in control of infectious diseases among Public health facilities in Kiambu County. The specific objectives were.

a) To determine the proportion of Health workers trained on Integrated Disease Surveillance and Response among Public health facilities in Kiambu County.

b) To determine the level of knowledge regarding Integrated Disease Surveillance and Response among Public health facilities in Kiambu County.

c) To establish the Health system factors influencing utilization of Integrated Disease Surveillance and Response data among Public health facilities in Kiambu County.

\section{MATERIALS AND METHODS}

A descriptive cross-sectional study design was used for this survey. The design was meant to describe the respondents' views and opinions on the utilization of Integrated Disease Surveillance and Response data among health workers in Public health facilities at a particular point in time. The dependent variable assessed was the utilization of Integrated Disease Surveillance and Response data to control infectious diseases. It was measured as a categorical variable as adequate utilization and inadequate utilization from the Likert scale for seven attributes. The overall utilization was obtained from averaging response statements on the utilization of integrated disease responses. Independent variables were;

a) Proportion of Public health workers trained on Integrated Disease Surveillance and Response was measured as a categorical variable of having trained or not trained.

b) Level of knowledge regarding Integrated Disease Surveillance and Response was determined by asking respondents 10 item questions regarding integrated disease surveillance. Respondents who got responses less than 4 questions correct were regarded as having poor knowledge. Those who got at 5-7 questions were regarded as having moderate knowledge, while those who got 8-10 questions were regarded as having good knowledge as ordinal variables.

c) Health system factors influencing the utilization of Integrated Disease Surveillance and Response data included Resource Availability, Technical determinants, and finance. They were measured as categorical nominal variables.

The study was carried out in Kiambu County, Kenya. There is a total of 108 Public health care facilities spread across the county categorized as follows: 70 Dispensaries offering Level 2 Services, 23 Health Centres providing Level 3 Services, 11 Hospital providing Level 4 Services and 3 Hospitals offering Level 5 Services. The study involved public health facilities, with key respondents being the health care workers providing curative and preventive health services 
within the selected health facilities. These people directly interact with the IDRS system through disease diagnosis, surveillance, or notification. Key respondents to the study were disease surveillance officers, Nurses, Public Health Officers, Community Health Extension Workers, Laboratory Technicians, Clinical Officers, Medical Officers, and Health record officers.

Stratified sampling technique was used to stratify the 108 health facilities into levels of health care while proportionate sampling was used to select 143 participants in the respective level of care. An interviewer-administered questionnaire was used to collect data which was entered and analysed using the Statistical Package for Social Sciences (SPSS) software version 20. Chi-square test of independence was used to assess the associations between utilization of IDSR data, training, level of knowledge and health system factors while Regression analysis was used to establish the predictors of utilization of IDSR data.

\section{RESULTS AND DISCUSSION}

\subsection{Utilization of Integrated Disease Surveillance and Response Data}

Utilization was operationalized as data for planning purposes, continuous training of health care workers, coordination of outbreak investigations, public sensitization on notifiable diseases, and review of procedures and policies at the county level. The outcome was measured as a binary variable wherein; utilization was classified as either adequate or inadequate of use of IDSR. Findings illustrate that overall, $64.9 \%$ of respondents claimed that there was inadequate utilization of IDSR data among health care workers. About a third were on the contrary. A close examination of utilization parameters reveals that more than half $(61.7 \%)$ of the sampled respondents disagreed that IDSR data in the study area had been used for planning for disease surveillance activities.

Table 1: Utilization of Integrated Disease Surveillance Data

\begin{tabular}{lccc}
\hline \hline Utilization Attributes & $\begin{array}{c}\text { Level of } \\
\text { Agreement }\end{array}$ & Frequency & $\begin{array}{c}\text { Percentage } \\
(\mathbf{\%})\end{array}$ \\
\hline \hline IDSR data adequately used in planning for & Agree & 54 & $38.3 \%$ \\
disease surveillance activities & Disagree & 87 & $61.7 \%$ \\
& Total & $\mathbf{1 4 1}$ & $\mathbf{1 0 0 \%}$ \\
\hline IDSR data informs continuous training needs for & Agree & 54 & $38.3 \%$ \\
health care workers & Disagree & 87 & $61.7 \%$ \\
& Total & $\mathbf{1 4 1}$ & $\mathbf{1 0 0 \%}$ \\
\hline IDSR data used to improve coordination of & Agree & 76 & $53.9 \%$ \\
outbreak investigation and response & Disagree & 65 & $46.1 \%$ \\
& Total & $\mathbf{1 4 1}$ & $\mathbf{1 0 0 \%}$ \\
\hline IDSR data used for Public sensitization on & Agree & 42 & $29.8 \%$ \\
notifiable disease prevention & Disagree & 99 & $70.2 \%$ \\
& Total & $\mathbf{1 4 1}$ & $\mathbf{1 0 0 \%}$ \\
\hline IDSR data used to inform infrastructural & Agree & 64 & $45.4 \%$ \\
improvement in implementing disease & Disagree & 77 & $54.6 \%$ \\
surveillance & Total & $\mathbf{1 4 1}$ & $\mathbf{1 0 0 \%}$ \\
\hline IDSR data used to inform resource mobilization & Agree & 39 & $27.7 \%$ \\
before, during and after outbreak investigations & Disagree & 102 & $72.3 \%$ \\
& Total & $\mathbf{1 4 1}$ & $\mathbf{1 0 0 \%}$ \\
\hline IDSR data informs the review of procedures and & Agree & 17 & $12.1 \%$ \\
policies for disease surveillance & Disagree & 124 & $87.9 \%$ \\
& Total & $\mathbf{1 4 1}$ & $\mathbf{1 0 0 \%}$ \\
\hline \hline
\end{tabular}


International Journal of Advances in Scientific Research and Engineering (ijasre), Vol 7 (4), April -2021

Table 2: Overall Utilization of Integrated Disease Surveillance Data

\begin{tabular}{ccc}
\hline Extent of utilization of IDSR Data & Frequency & Percent \\
\hline Agree & 49 & $35.1 \%$ \\
Disagree & 92 & $64.9 \%$ \\
\hline Total & $\mathbf{1 4 1}$ & $\mathbf{1 0 0 \%}$ \\
\hline \hline
\end{tabular}

1. Proportion of health care workers trained in Integrated Disease Surveillance and Response

This study has established that a large proportion of respondent $(86.5 \%)$ had not been trained on integrated diseases surveillance within the past I year. When stratified across the health facilities level, those working in level V facility had not been trained entirely. Integrated disease surveillance is wholly managed at the national disease surveillance unit responsible for training purposes. The decentralization of health services has created parallel reporting channels, and as such, conflicts of interest may arise between the two levels of government. Consequently, refresher training opportunities for integrated disease surveillance become limited and far in between. Lack of training compounds several aspects of surveillance.

Table 3: Proportion of health care workers trained on Integrated Disease Surveillance and Response

\begin{tabular}{cccc}
\hline Facility Type & Training on IDSR & Frequency & Percent \\
\hline \hline \multirow{3}{*}{ Level II } & Not Trained & 25 & $71.4 \%$ \\
& Trained & 10 & $28.6 \%$ \\
& Total & 35 & $100.0 \%$ \\
\hline \multirow{2}{*}{ Level III } & Not Trained & 30 & $83.3 \%$ \\
& Trained & 6 & $16.7 \%$ \\
& Total & 36 & $100.0 \%$ \\
\hline \multirow{3}{*}{ Level IV } & Not Trained & 34 & $91.9 \%$ \\
& Trained & 3 & $8.1 \%$ \\
& Total & 37 & $100.0 \%$ \\
\hline \hline Level V & Not Trained & 33 & $100.0 \%$ \\
\hline \hline
\end{tabular}

Table 4: Overall Proportion of health care workers trained on Integrated Disease Surveillance and Response

\begin{tabular}{ccc}
\hline Training on IDSR & Frequency & Percent \\
\hline Not Trained & 122 & $86.5 \%$ \\
Trained & 19 & $13.5 \%$ \\
\hline Total & $\mathbf{3 6}$ & $\mathbf{1 0 0 . 0 \%}$ \\
\hline
\end{tabular}

\subsection{Level of Knowledge and utilization of Integrated Disease Surveillance and Response Data}

This study assessed health care workers' level of knowledge based on the disease target for elimination and eradication. Findings show that, overall, about three-quarters of respondents (75.2\%) had a moderate level of knowledge of notifiable diseases. Across all cadres, Clinical officers, Nurses and Doctors exhibited good knowledge of notifiable diseases. Inferential analysis in the current study has found a statistical difference with the utilization of 
International Journal of Advances in Scientific Research and Engineering (ijasre), Vol 7 (4), April -2021

IDSR data. Logistic regression analysis establishes that the level of knowledge on matters of IDSR is a predictor of utilizing IDSR data for decision making.

Table 5: Level of knowledge regarding Integrated Disease Surveillance and Response among Health workers

\begin{tabular}{|c|c|c|c|c|}
\hline Gender & Cadre & Level of knowledge & Frequency & Percent \\
\hline \multirow{16}{*}{ Female } & \multirow{2}{*}{ Clinical Officers } & Good Knowledge & 4 & $50.0 \%$ \\
\hline & & Moderate Knowledge & 4 & $50.0 \%$ \\
\hline & Community Health Officer & Moderate Knowledge & 1 & $100.0 \%$ \\
\hline & \multirow{3}{*}{$\begin{array}{l}\text { Laboratory } \\
\text { Technologist/Technician }\end{array}$} & Poor Knowledge & 1 & $6.7 \%$ \\
\hline & & Good Knowledge & 3 & $20.0 \%$ \\
\hline & & Moderate Knowledge & 11 & $73.3 \%$ \\
\hline & \multirow{2}{*}{ Medical Officer } & Good Knowledge & 1 & $33.3 \%$ \\
\hline & & Moderate Knowledge & 2 & $66.7 \%$ \\
\hline & \multirow{3}{*}{ Nurse } & Poor Knowledge & 1 & $2.3 \%$ \\
\hline & & Good Knowledge & 8 & $18.2 \%$ \\
\hline & & Moderate Knowledge & 35 & $79.5 \%$ \\
\hline & Nutritionist & Moderate Knowledge & 2 & $100.0 \%$ \\
\hline & \multirow{2}{*}{$\begin{array}{l}\text { Pharmaceutical } \\
\text { Technologist }\end{array}$} & Good Knowledge & 2 & $40.0 \%$ \\
\hline & & Moderate Knowledge & 3 & $60.0 \%$ \\
\hline & \multirow{2}{*}{$\begin{array}{l}\text { Public Health } \\
\text { Officer/Technician }\end{array}$} & Good Knowledge & 2 & $22.2 \%$ \\
\hline & & Moderate Knowledge & 7 & $77.8 \%$ \\
\hline \multirow{13}{*}{ Male } & \multirow{3}{*}{ Clinical Officers } & Poor Knowledge & 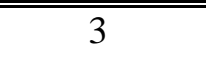 & $27.3 \%$ \\
\hline & & Good Knowledge & 3 & $27.3 \%$ \\
\hline & & Moderate Knowledge & 5 & $45.5 \%$ \\
\hline & $\begin{array}{l}\text { Laboratory } \\
\text { Technologist/Technician }\end{array}$ & Moderate Knowledge & 8 & $100.0 \%$ \\
\hline & Medical Officer & Moderate Knowledge & 4 & $100.0 \%$ \\
\hline & \multirow{2}{*}{ Nurse } & Good Knowledge & 3 & $27.3 \%$ \\
\hline & & Moderate Knowledge & 8 & $72.7 \%$ \\
\hline & Nutritionist & Moderate Knowledge & 1 & $100.0 \%$ \\
\hline & \multirow{3}{*}{$\begin{array}{l}\text { Pharmaceutical } \\
\text { Technologist }\end{array}$} & Poor Knowledge & 1 & $16.7 \%$ \\
\hline & & Good Knowledge & 1 & $16.7 \%$ \\
\hline & & Moderate Knowledge & 4 & $66.7 \%$ \\
\hline & \multirow{3}{*}{$\begin{array}{l}\text { Public Health } \\
\text { Officer/Technician }\end{array}$} & Good Knowledge & 2 & $15.4 \%$ \\
\hline & & Moderate Knowledge & 11 & $84.6 \%$ \\
\hline & & Total & 141 & $100 \%$ \\
\hline
\end{tabular}

Table 6: Overall level of knowledge regarding Integrated Disease Surveillance and Response among Health workers

\begin{tabular}{ccc}
\hline Level of knowledge on IDSR & Frequency & Percentage \\
\hline Poor Knowledge & 6 & $4.3 \%$ \\
Good Knowledge & 29 & $20.6 \%$ \\
Moderate Knowledge & 106 & $75.2 \%$ \\
\hline Total & $\mathbf{1 4 1}$ & $\mathbf{1 0 0 \%}$ \\
\hline \hline
\end{tabular}


International Journal of Advances in Scientific Research and Engineering (ijasre), Vol 7 (4), April -2021

\subsection{Health Systems factors influencing the utilization of Integrated Disease Surveillance and Response data}

The success of effective disease surveillance is dependent on the availability of a responsive health system. Finance is a core component of a responsive health system as a key determinant of an integrated disease surveillance system performance. The present study has established that many healthcare workers asserted that there were inadequate funds for IDSR activities within the county. Limited allocation of supplies for IDSR, was also mentioned by about half of the respondents. The unavailability of essential supplies for IDSR activities increases the probability of ineffective response to potential epidemics should it occur. The availability of job aids improves the technical capacities of health workers. About $75 \%$ of health workers attested that job aids for integrated disease surveillance and response were available in plenty at their workplaces. Inferential analysis at both bivariate and logistic regression did not establish a statistical difference.

Table 7: Health system factors influencing the utilization of Integrated Disease Surveillance and Response data.

\begin{tabular}{lccc}
\hline $\begin{array}{l}\text { Health system } \\
\text { factors }\end{array}$ & Perceived Availability & Frequency & Percent \\
\hline \hline & & 18 & $12.8 \%$ \\
Job Aids for & No at all & 17 & $12.1 \%$ \\
Case Definitions & Not for all Diseases & 106 & $75.2 \%$ \\
& Yes & $\mathbf{1 4 1}$ & $\mathbf{1 0 0 . 0 \%}$ \\
\hline & Total & 27 & $19.1 \%$ \\
Supplies for & Non available & 37 & $26.2 \%$ \\
IDSR Activities & Supplies adequate & 77 & $54.6 \%$ \\
& Supplies inadequate & $\mathbf{1 4 1}$ & $\mathbf{1 0 0 . 0 \%}$ \\
\hline Funds for IDSR & Total & 64 & $45.0 \%$ \\
Activities & Funds are inadequate & 68 & $48.6 \%$ \\
& Do not Know & 9 & $6.4 \%$ \\
& Funds are adequate & $\mathbf{1 4 1}$ & $\mathbf{1 0 0 \%}$ \\
\hline \hline
\end{tabular}

\subsection{Test of Associations between independent and dependent variables}

Table 8 shows the bivariate analysis between independent and dependent variables. Chi-square analysis shows that the respondent's duration of practice $\chi^{2}(0.227 d f=2, p=0.045)$ and level of knowledge on IDSR were associated with utilization of IDSR data $\chi^{2}(0.227 \mathrm{df}=2, p=0.048)$. 
International Journal of Advances in Scientific Research and Engineering (ijasre), Vol 7 (4), April -2021

Table 8: Cross-tabulations between independent and Dependent Variables

\begin{tabular}{|c|c|c|c|}
\hline \multirow[b]{2}{*}{ Age } & \multicolumn{2}{|c|}{$\begin{array}{l}\text { Utilization of Integrated Disease } \\
\text { Surveillance and Response Data }\end{array}$} & \\
\hline & $\begin{array}{c}\text { Adequate } \\
\text { Utilization }(\%)\end{array}$ & $\begin{array}{c}\text { Inadequate } \\
\text { Utilization (\%) }\end{array}$ & \\
\hline 20-29 Years & $10(45.5)$ & $12(54.5)$ & \multirow{4}{*}{$\begin{array}{c}3.268(d f=4) \\
(p=0.514)\end{array}$} \\
\hline 30-39 Years & $30(54.5)$ & $25(45.5)$ & \\
\hline 40-49 Years & $24(57.1)$ & $18(42.9)$ & \\
\hline Above 50 Years & $14(66.7)$ & $7(33.3)$ & \\
\hline \multicolumn{4}{|l|}{ Gender } \\
\hline Female & $50(57.5)$ & $37(42.5)$ & \multirow{2}{*}{$\begin{array}{c}0.426(d f=1) \\
(p=0.514)\end{array}$} \\
\hline Male & $28(51.9)$ & $26(48.1)$ & \\
\hline \multicolumn{4}{|l|}{ Cadre of Respondents } \\
\hline Clinical Officers & $10(52.6)$ & $9(47.4)$ & \multirow{7}{*}{$\begin{array}{c}2.057(d f=6) \\
(p=0.957)\end{array}$} \\
\hline Community Health Officer & $1(100)$ & $0(0)$ & \\
\hline Laboratory Technologist & $13(56.5)$ & $10(43.5)$ & \\
\hline Medical Officer & $4(57.1)$ & $3(42.9)$ & \\
\hline Nurse & $31(56.4)$ & $24(43.6)$ & \\
\hline Pharmacy Technologist & $7(63.6)$ & $4(36.4)$ & \\
\hline Public Health Officer & $11(50)$ & $11(50)$ & \\
\hline \multicolumn{4}{|l|}{ Duration worked } \\
\hline 10-20 Years & $11(64.7)$ & $6(35.3)$ & \multirow{4}{*}{$\begin{array}{c}2.437(d f=3) \\
(p=0.045)\end{array}$} \\
\hline 5-10 Years & $19(59.4)$ & $13(40.6)$ & \\
\hline Less than 5 years & $47(53.4)$ & $41(46.6)$ & \\
\hline More than 20 Years & $1(25)$ & $3(75)$ & \\
\hline \multicolumn{4}{|l|}{ Training on IDSR } \\
\hline Trained on IDSR & $83(69.2 \%)$ & $37(30.8 \%)$ & \multirow{2}{*}{$\begin{array}{c}0.04(d f=1) \\
p=0.948\end{array}$} \\
\hline Not Trained on IDSR & $13(68.4 \%)$ & $6(31.6 \%)$ & \\
\hline \multicolumn{4}{|l|}{ Level of Knowledge on IDSR } \\
\hline Poor Knowledge & $4(66.7 \%)$ & $2(33.3 \%)$ & \multirow{3}{*}{$\begin{array}{c}0.227(d f=2) \\
p=0.048\end{array}$} \\
\hline Good Knowledge & $21(72.4 \%)$ & $8(27.6 \%)$ & \\
\hline Moderate Knowledge & $72(67.9 \%)$ & $34(32.1 \%)$ & \\
\hline \multicolumn{4}{|l|}{ Availability of Funds for IDSR } \\
\hline Not aware & $45(66.2 \%)$ & $23(33.8 \%)$ & \multirow{2}{*}{$\begin{array}{c}1.466(d f=2) \\
p=0.480\end{array}$} \\
\hline Funds are adequate & $5(55.6 \%)$ & $4(44.4 \%)$ & \\
\hline
\end{tabular}

Logistic regression analysis was used to establish the predictors of utilization of IDSR data. Regression analysis illustrates that respondents' Cadre was a predictor of the utilization of IDSR data. The log odds of the utilization of IDSR increase by 0.827 with respect to the Cadre of health care workers. The level of knowledge on IDSR was a predictor of the utilization of integrated disease surveillance data. 
International Journal of Advances in Scientific Research and Engineering (ijasre), Vol 7 (4), April -2021

Table 9: Logistic Regression analysis of predictors of Utilization of Integrated Disease Surveillance and Response data

\begin{tabular}{lcccc}
\hline \multicolumn{1}{c}{ Variables } & Sig. & Exp (B) & \multicolumn{2}{c}{ 95\% C.I. for EXP(B) } \\
\hline Level of Facility & 0.388 & 0.848 & 0.583 & Upper \\
Age & 0.308 & 1.226 & 0.828 & 1.233 \\
Gender & 0.455 & 1.342 & 0.620 & 1.816 \\
Cadre & $\mathbf{0 . 0 4 1}$ & 0.827 & 0.689 & 0.905 \\
Level of Knowledge & $\mathbf{0 . 0 2 3}$ & 1.550 & 0.696 & 3.449 \\
Availability of Supplies & 0.679 & 0.897 & 0.537 & 1.499 \\
for IDSR & 0.898 & 1.078 & 0.339 & 3.428 \\
Training in IDSR & 0.401 & 0.228 & & \\
Constant & & & \\
\hline
\end{tabular}

\section{CONCLUSION}

Utilization of IDSR data collected in Public health facilities is inadequate and available data has not been adequately utilized to inform action plans, public education, and resource mobilization. A large proportion of health care workers in the study area have not been adequately trained for a significant proportion of the time. Study participants had moderate knowledge of IDSR function, with a majority being conversant with all notifiable diseases. The level of knowledge on matters of IDSR is a predictor of utilizing IDSR data for decision making. Healthcare workers identified the inadequacy of essential supplies. Financing for IDSR activities is perceived to be insufficient.

\section{REFERENCES}

[1] Adokiya Martin Nyaaba, John Koku Awoonor-Williams, Inuwa Yau Barau, Claudia Beiersmann, and Olaf Mueller (2015); Evaluation of the integrated disease surveillance and response system for infectious diseases control in northern Ghana

[2] Athman Juma Mwatondo, Zipporah Ng'ang'a, Caroline Maina, Lyndah Makayotto, Moses Mwangi, Ian Njeru,and Wences Arvelo (2013); Factors associated with adequate weekly reporting for disease surveillance data among health facilities in Nairobi County, Kenya.

[3] MOH Kenya (2012). Technical Guidelines for Integrated Disease Surveillance and Response in Kenya-2nd Edition. Ministry of Public Health and Sanitation.

[4] Bruckner C, Checchi F. (2011); Detection of infectious disease outbreaks in twenty-two fragile states, 20002010: a systematic review. Conflict and Health. 